\title{
Mastopexia e Implante Resultados a Largo Plazo
}

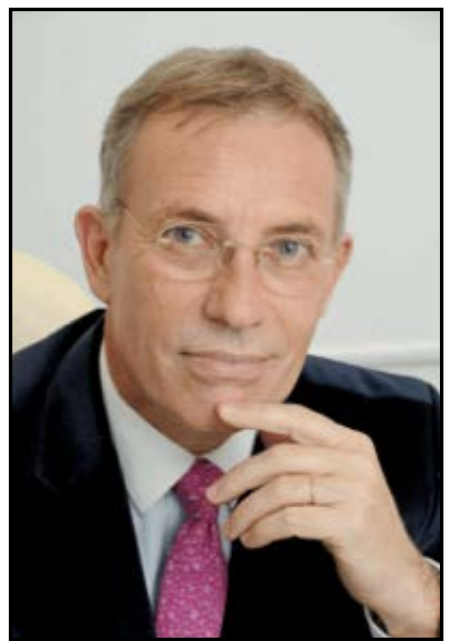

Ernesto A. Moretti (Jefe de Servicio), David Chanchí, Dario Alarcon, Julietta Settecasi, Jonathan Camargo (Médicos

Residentes)

Servicio de Cirugía Plástica

Hospital Privado de Rosario, Grupo Gamma,

Roca 2440

Rosario, Santa Fe, Argentina

\section{Introducción}

En vista que la cirugía de aumento mamario viene en ascenso en las ultimas décadas, es un reto para el cirujano plástico obtener buenos resultados con mínimas incisiones. Una de las preguntas de nuestras pacientes en el momento de realizar la consulta sobre aumentar el tamaño del busto y corregir la ptosis es sobre la cicatriz resultante. Temen abordajes grandes y heridas visibles que entorpezcan la apariencia estética de la mama. El desafío es colocar el implante y subir la mama al mismo tiempo.

Dependiendo el grado de ptosis se utilizan diferentes técnicas quirúrgicas, desde cicatrices periareolar, verticales y en T invertida.

Planteamos en nuestra presentación previa (1), un nuevo procedimiento quirúrgico de mastopexia con abordaje periareolar superior y colocación de implante para el manejo de ptosis mamaria leve a moderada.

El objetivo del presente articulo es demostrar los resultados con mínimas cicatrices y dilucidar el comportamiento a lo largo del tiempo.

\section{Material y Métodos}

Durante el período 2010-2017 se realizaron 82 procedimientos usando nuestra técnica de colocación de 
implantes y corrección .istanc largo s y en $T$ invertida.de ptosis mamaria leve (distancia del manubrio esternal al pezón entre 22 y $26 \mathrm{~cm}$ ). En las imágenes y diseños se muestran los pasos de la técnica en forma secuencial.

Las pacientes intervenidas se encuentran entre 22 y 55 años de edad, todas manifestaban el deseo de ascenso y mejoría en el aspecto del polo superior mamario. Se realizó un abordaje periareolar superior con creación del colgajo de forma de trapecial a nivel del polo superior e implante mamario texturizado de gel de silicona en plano subfacial. (Fotos intraoperatorias del procedimiento). El tamaño del implante fue elegido por la paciente con orientación del cirujano oscilando entre 220 y 420 cc. En el $100 \%$ de los casos se optó por colocar implantes redondos, marca Nagor (Impleo, Perfiles HR y EHR) para mejorar el llenado del polo superior de la mama y evitar la apariencia ptosica que brindan los de tipo anatómico. El seguimiento fue a 6,12 y 24 meses (Casos presentados)

\section{Discusión}

Como se comentó en el articulo anterior del mismo autor (1) esta técnica quirúrgica esta inspirada en procedimientos antiguos descritos por Hollander en 1924 y modificados por Weinhold en 1926 y Noel en 1928 donde se abordaba por vía periareolar superior y se resecaba exclusivamente el tejido cutáneo necesario para el reposicionamiento de la areola. En todas estas descripciones, lo único que se modificaba era la posición del complejo. A partir de la aparición de los implantes, el sostén de los mismos, en los casos de ptosis leves, usando solo el abordaje periareolar superior, provoca a corto plazo la recidiva de la ptosis. Este hecho tiene como factor la falta de sostén interno. Es por ello que se diseñó en forma innovadora el colgajo de forma de trapecial de base superior mamario para sostén de la mama por encima del implante colocado. Así se logra el mantenimiento del implante en una altura correcta, evitando la ptosis y el alargamiento de la areola.

Se muestran una serie de fotos de pacientes a quienes se les hizo seguimiento a 6,12 y 24 meses después de la intervención quirúrgica.

\section{Conclusión}

Las pacientes seleccionadas para este procedimiento tienen menos de $5 \mathrm{~cm}$ de ascenso del complejo areola pezón para evitar la distorsión del mismo, útil en ptosis mamaria leve con deseo de aumento mamario evitando la cicatriz vertical. Es una técnica fácilmente reproducible que requiere escasa curva de aprendizaje, mínima cicatriz resultante y se mantiene en el tiempo.

\section{Bibliografía}

1- Mastopexia e Implate: Un nuevo procedimiento para evitar la cicatriz vertical. Rev Boliviana de Cirugía Plástica, pp. 17-20, Vol 1, $\mathrm{n}: 2,2016$ 

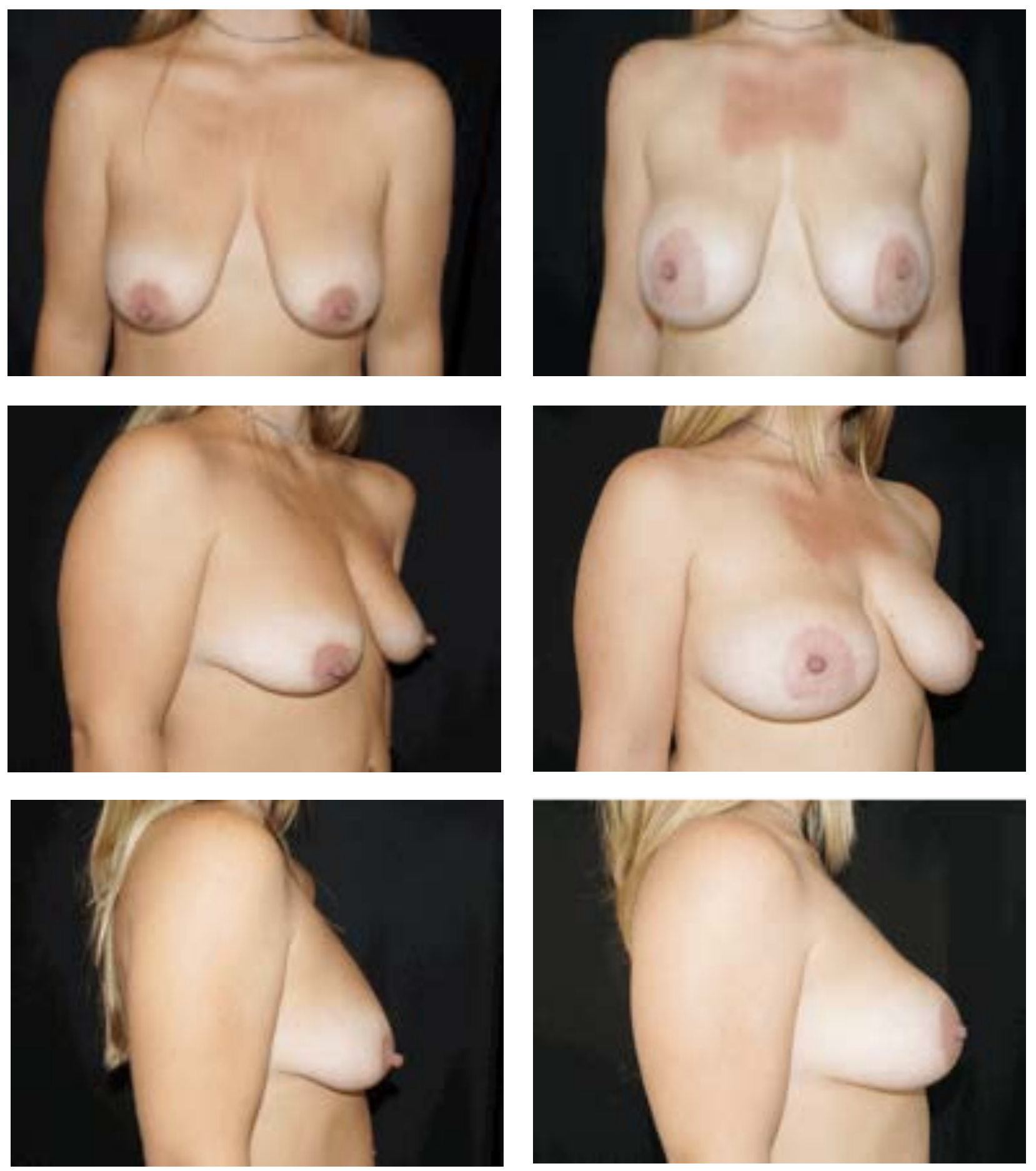

\section{Caso 1}

Paciente de 38 años, lactancia previa en 2 oportunidades. Preoperatorio y postoperatorio a los 3 meses. Implante Nagor Impleo 360 HR (redondo, perfil alto). 

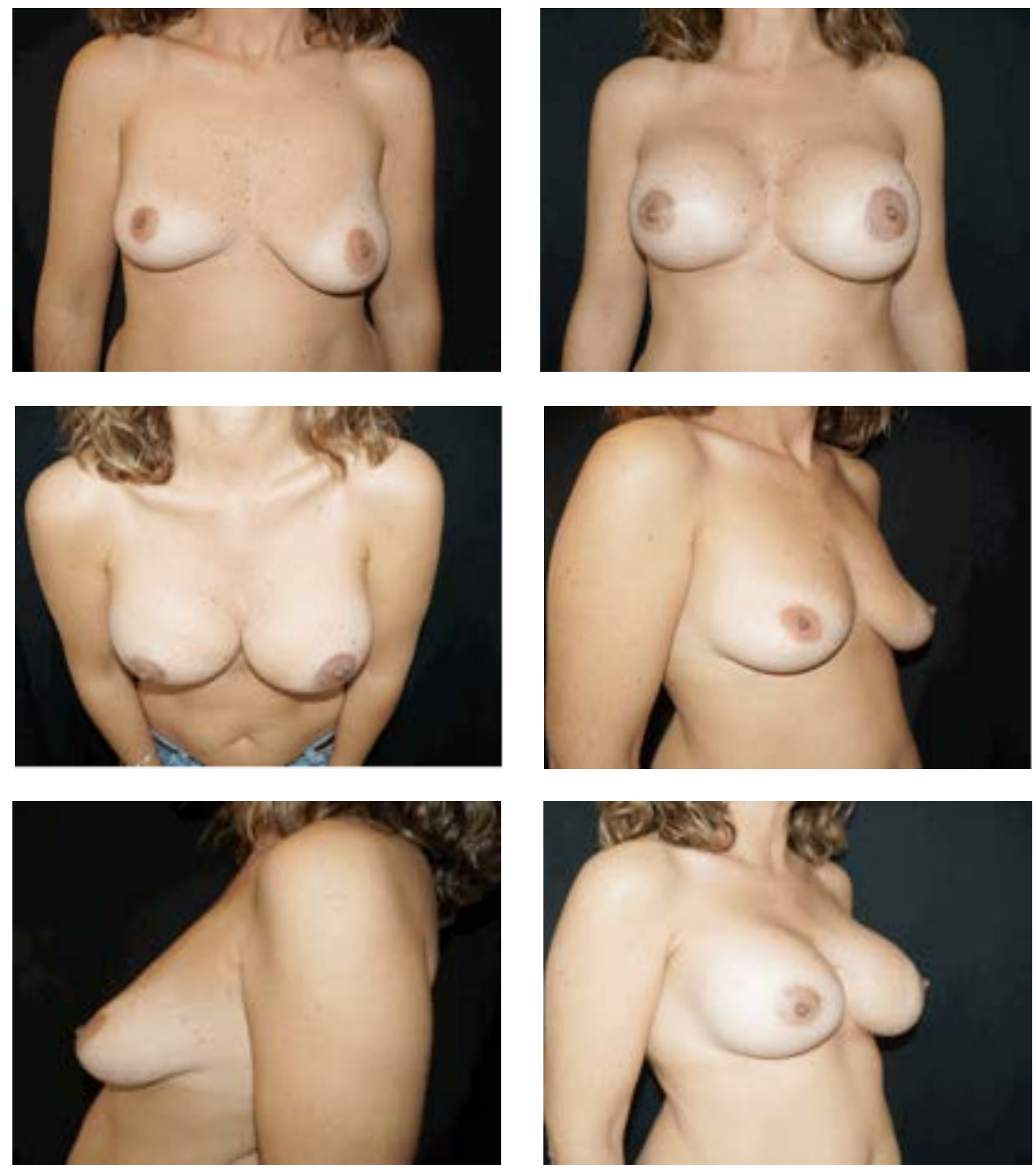

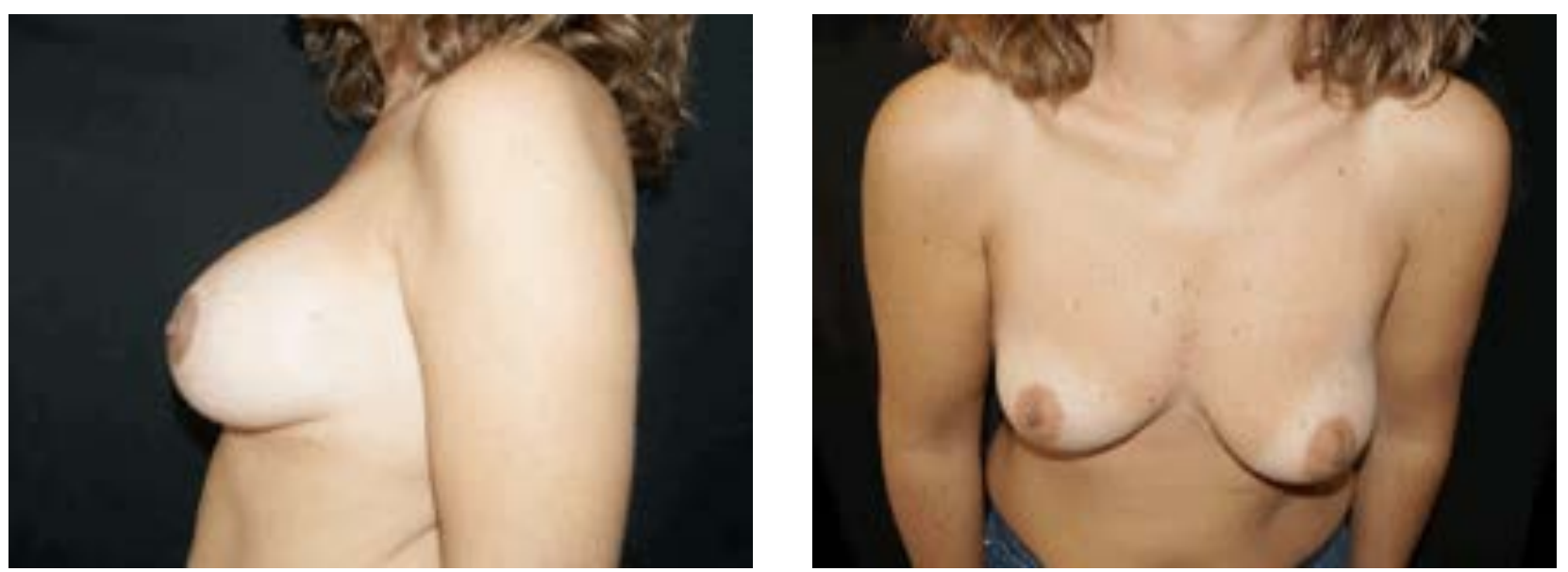

\section{Caso 2}

Paciente de 28 años con asimetría mamaria primaria. En mama derecha colocación de implante Nagor Impleo 420 EHR (redondo y perfil extra alto) y mama izquierda colocación de implante Nagor 390 en forma conjunta con mastopexia periareolar superior. Control postoperatorio a los 6 meses. 

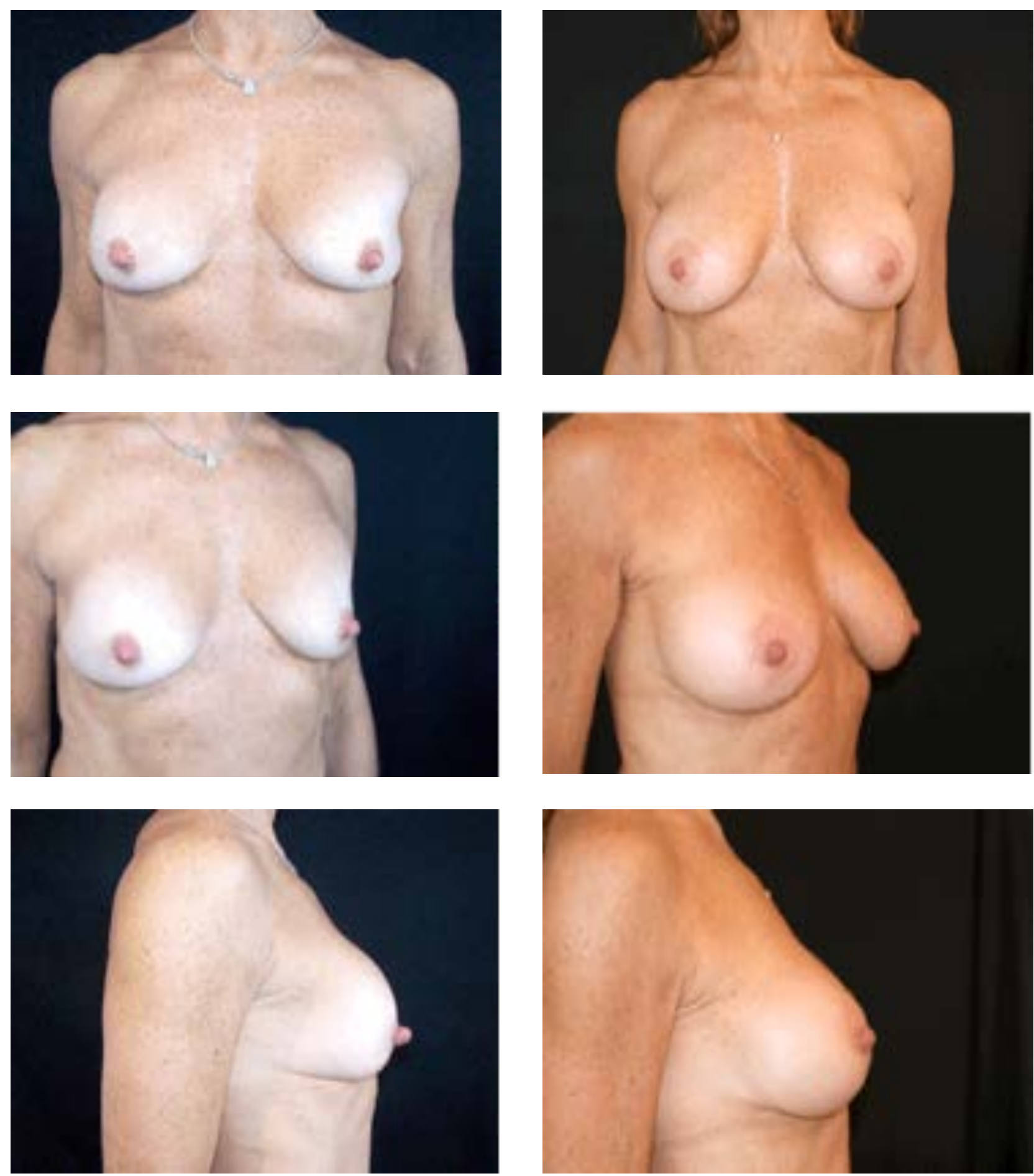

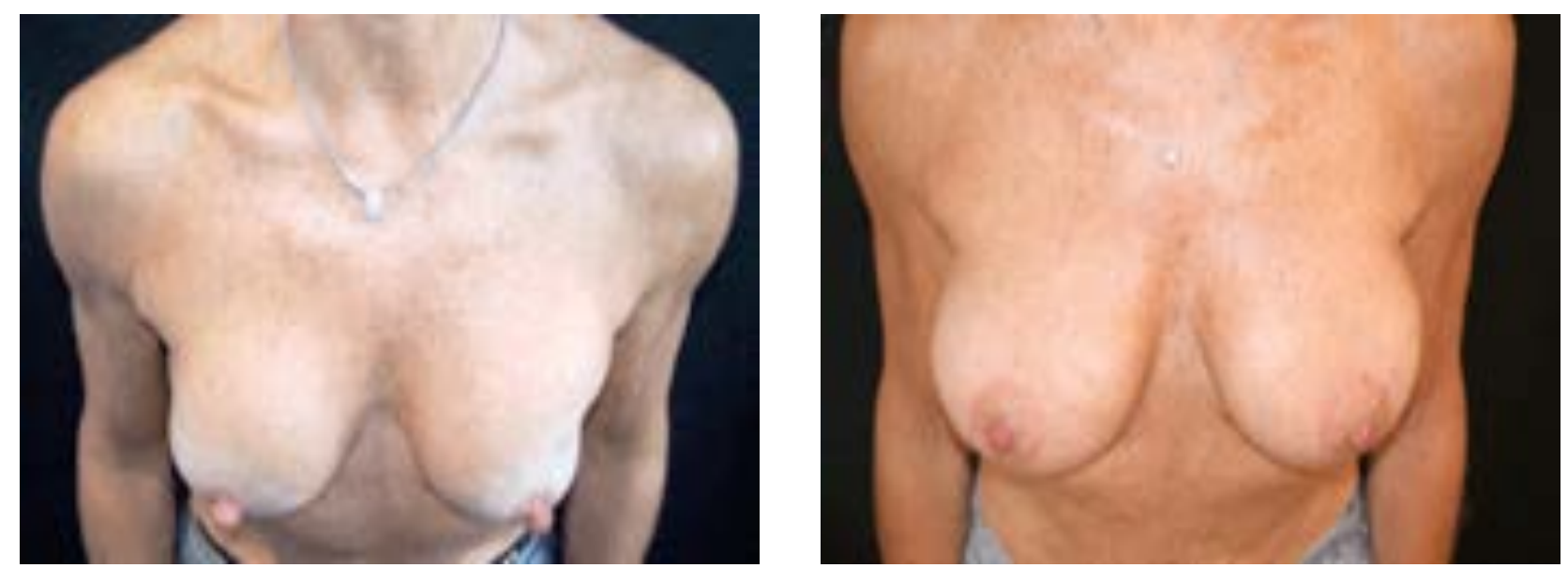

Caso 3

Paciente de 44 años con implantes redondos previos colocados hace 15 años. Recambio de implantes por implantes anatómicos Nagor Impleo HR 330 y mastopexia periareolar superior. Postoperatorio a los 12 meses. 